\title{
Skrb za drevesa v urbanem okolju
}

\section{Andreja KAVČIC $\check{1}^{*}$}

$\mathrm{Na}$ Gozdarskem inštitutu Slovenije je 1. oktobra 2018 potekalo strokovno predavanje o drevesih v urbanem okolju, ki ga je organiziralo podjetje Tisa, d. o. o.. Predaval je dr. Frank Rinn iz nemškega podjetja RinnTech, ki razvija opremo za dendrokronologijo in drevesno diagnostiko. Dr. Rinn je svetovno priznan strokovnjak za drevesno in lesno biomehaniko, izumitelj, sodni izvedenec, diagnostik, avtor številnih člankov in predavatelj.

Drevje v urbanem okolju ima izjemno pomembno ekološko in socialno vlogo. Urbana drevesa med drugim ugodno vplivajo na klimo, izboljšujejo kvaliteto zraka in zadržujejo vlago, so del kulturne krajine in dajejo mestom svojstven značaj. Nenazadnje pa imajo drevesa tudi ugoden vpliv na zdravje in počutje ljudi (Slika 1). Z drevjem v urbanem okolju se ukvarja arboristika (ang.: arboriculture, nem.: Baumpflege), ki pomeni gojenje in raziskovanje lesnatih rastlin - ponavadi drevja. Arboristika je praviloma omejena na urbana območja in se osredotoča na posamezna drevesa. Vključuje izbiro in zasaditev, gnojenje in zalivanje ter ostalo redno oskrbo, zaščito pred abiotskimi poškodbami, obvladovanje bolezni in škodljivcev, obrezovanje, oblikovanje, posek, ... skratka, stalno skrb za ohranjanje optimalnega zdravstvenega stanja posameznih lesnatih rastlin s ciljem njihovega dolgotrajnega ohranjanja v prostoru. Arboristika ni in nikakor ne sme biti zgolj slabo premišljeno obžagovanje in podiranje dreves! $Z$ naraščajočo urbanizacijo postaja arboristika vse bolj pomembna panoga (Slika 2).

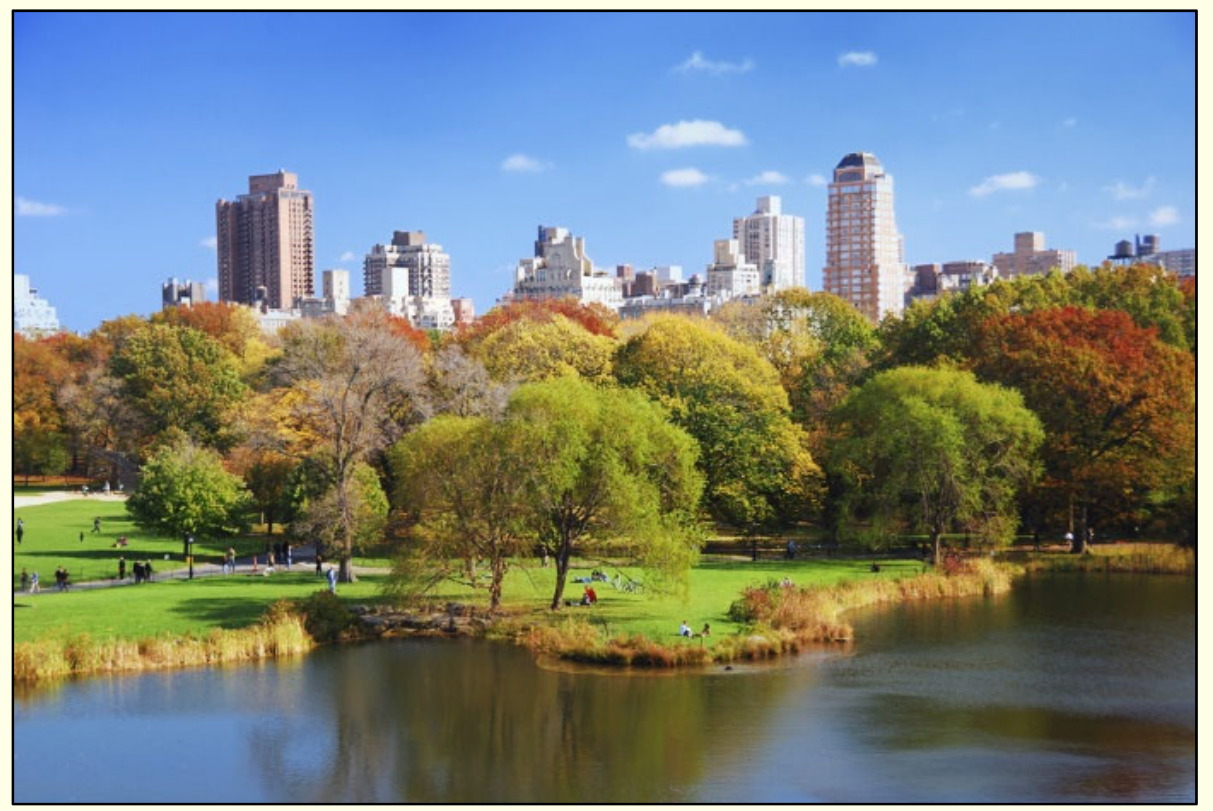

Slika 1: Drevesa v urbanem okolju ugodno vplivajo na življenje ljudi (Vir: www.citibikenyc.comridescentral-park-lower-loop).

$\mathrm{Z}$ arboristiko se ukvarjajo arboristi. Delo arboristov je zahtevno in zaradi dela na višini tudi nevarno, zato je primerno samo za dobro strokovno usposobljene in fizično pripravljene osebe. Ker arboristika zadeva drevesa na javnih površinah, morajo arboristi dobro poznati tudi ustrezno zakonodajo, da ne pride do nepotrebih pravnih zapletov. V urbanih območjih ima zelo pomembno vlogo estetski vidik zelenih površin, zato morajo imeti arboristi poleg širokega strokovnega znanja in različnih tehničnih veščin tudi smisel za estetiko (Slika 3).

Drevesa so tako kot vsi drugi organizmi podvržena vplivu številnih abiotičnih in biotičnih dejavnikov. Nekateri od njih na drevo vplivajo ugodno (voda, hranila, svetloba, toplota, ...) drugi pa povzročajo poškodbe, deformacije in odmiranje delov ali pa celega drevesa (mehanske poškodbe, bolezni, škodljivci, ...) (Slika 4). Nekateri od slednjih imajo znaten negativen vpliv na mehanske lastnosti drevesa, na njegovo trdnost in stabilnost. V okolju, kjer je prisoten človek, lahko drevo, ki ima zmanjšane mehanske lastnosti, poškoduje človeka ali njegovo lastnino, na kar kažejo številni primeri poškodb infrastrukture in smrti ljudi zaradi lomljenja vej in podiranja dreves ne samo v tujini, ampak tudi pri nas (Slika 5). Naloga arboristov je tako tudi, da na drevesu čim prej zaznajo morebitne spremembe, predvidijo njihov nadaljnji razvoj in natančno ocenijo stopnjo tveganja drevesa za okolico (arboristična diagnostika) (Slika 
6) ter z ustreznimi ukrepi odstranijo kakršnokoli nevarnost, ki je povezana s tem drevesom (Slika 7).

Za urbano drevje so tipične mehanske poškodbe korenin (npr. nastale ob izkopih, zaradi zbijanja tal na območju koreninskega sistema), spodnjega dela debla (npr. zaradi trkov vozil in gradbene mehanizacije, vandalizma) in krošnje (zlasti zaradi nestrokovnega obrezovanja). V urbanih območjih ima videz praviloma prednost pred funkcionalnostjo, zato so v mestih običajne zasaditve velikega deleža dreves ene vrste, ki so pogosto tudi iste starosti. Zaradi istega razloga so pogoste tudi zasaditve drevesnih vrst, za katere izbrana lokacija ni ekološko ustrezna. Tako monokulture kot zasaditve neustreznih drevesnih vrst vodijo v poškodbe in slabše zdravstveno stanje urbanega drevja, ki je zato bolj dovzetno za negativne vplive abiotičnih in biotičnih dejavnikov (Slika 8).

V mnogih mestih rastejo mogočna stoletna stara drevesa, ki imajo veliko kulturno in naravno vrednost in dajejo mestom poseben pečat. Poleg tega, da so bila taka drevesa $v$ stoletjih podvržena številnim negativnim vplivom, je s starostjo začela usihati tudi njihova vitalnost. Kljub mogočnemu videzu postajajo vse bolj dovzetna za bolezenske okužbe in napade škodljivcev. Na takih drevesih so pogoste deformacije in nepravilna rast, izvotlitve debla, pojavlja se odmiranje korenin, sušenje krošnje, lomljenje vej, ... (Slika 9)

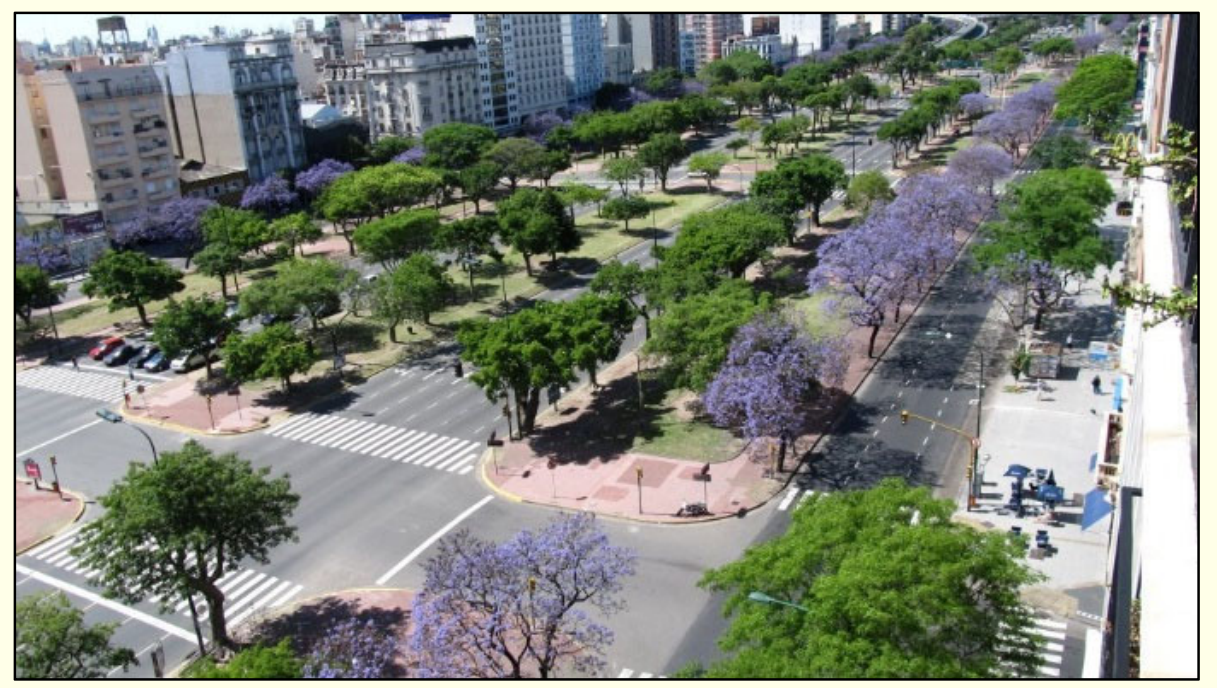

Slika 2: Z naraščajočo urbanizacijo postaja arboristika vse bolj pomembna

(Foto: Mauricio V. Genta, es.wikipedia.org).

Dr. Frank Rinn nam je predstavil, kako s posebnimi tehnikami in orodji arboristi ocenijo stopnjo tveganja drevesa za okolico na podlagi analize njegovih mehanskih lastnosti (Slika 10). Po njegovem mnenju je dobro poznavanje anatomije lesa in zakonitosti rasti lesnatih rastlin nujna podlaga za oceno tveganja, saj le tako lahko izberemo ustrezno metodo in optimalno ocenimo stanje drevesa. Pojasnil je, da vsako drevo z očitnimi in obsežnimi nepravilnostim oz. poškodbami, zaradi katerih je na videz zelo nestabilno, ni nujno nevarno, kar je nazorno razložil s primeri in enostavnimi matematičnimi izračuni. Pogosto se izkaže, da so taka drevesa celo bolj stabilna kot na videz popolnoma zdrava in pravilno oblikovana mlajša drevesa. In obratno, včasih lahko že majhne poškodbe oz. nepravilnosti, ki jih s prostim očesom skoraj ne opazimo, zelo zmanjšajo stabilnost drevesa. Izvedeli smo še, da na stabilnost drevesa vplivajo tudi položaj deformacije ter oblika rasti in struktura lesa, zato stabilnost drevesa ni nujno enaka v vseh smereh. $\mathrm{Z}$ enostavnim izračunom smo prišli do zaključka, da je stabilnost drevesa premosorazmerna $\mathrm{z}$ gostoto lesa in debelino debla ter obratno sorazmerna z višino drevesa. Ugotovili smo, da ima debelina debla na stabilnost drevesa izrazito večji vpliv kot višina drevesa. Poenostavljeno rečeno, starejše kot je drevo, bolj je mehansko stabilno in večje deformacije in poškodbe (tipične za zelo stara drevesa so na primer obsežne izvotlitve v deblu) lahko vzdrži (Slika 11).
Predavatelj je tudi ovrgel mit, da je zdravo drevo vedno tudi varno. Kot primer je navedel starejša drevesa, ki so se v desetletjih rasti optimalno prilagodila na lokalne razmere. Če se te nenadoma radikalno spremenijo (npr. zaradi odstranitve sosednjih dreves ali izgradnje visokih stavb se poveča izpostavljenost vetrovom ali izpostavljenost vetrovom visokih jakosti zaradi ustvarjanja vetrovnih koridorjev), se lahko stabilnost drevesa zelo zmanjša in to kljub neoporečnemu zdravstvenemu stanju postane nevarno za okolico.

Dr. Frank Rinn je v osnovi fizik in inovator, zato ni presenetljivo, da se je osredotočal $v$ glavnem na anatomijo lesa in mehanske lastnosti dreves v urbanih območjih - predstavil nam je tudi nekaj naprav in merilnih inštrumentov ter specialno računalniško opremo, ki jih je sam patentiral in jih uporablja pri svojem delu. Vendar pa arboristična diagnostika zahteva več kot samo poznavanje anatomije in mehanskih lastnosti lesa ter računaje z dimenzijami drevesa. Namreč, na drevesu so prisotni tudi številni organizmi, ki tako ali drugače vplivajo nanj. Medtem ko nekateri niso nevarni, določene bolezni in škodljivci lahko drevo oslabijo, povzročijo sušenje in lomljenje vej in celo propad celega drevesa. Številne škodljive organizme je lahko spregledati, ker se nahajajo na območju korenin ali v lesu ali pa zato, ker so spremembe, ki jih povzročajo, enake spremembam zaradi vpliva abiotičnih dejavnikov (Slika 12). Spremembe za- 
radi nekaterih so hitre in očitne, zaradi drugih pa se spremembe na drevesu pojavijo šele po daljšem času. V arboristiki je zato treba poznati in upoštevati ne le anatomijo lesa in zakonitosti rasti drevja, ampak tudi organizme, ki se na drevesih pojavljajo (Slika 13), njihovo biologijo in simptome, ki jih povzročajo, ter njihov kratkoročni in dolgoročni vpliv na drevo. Šele na podlagi

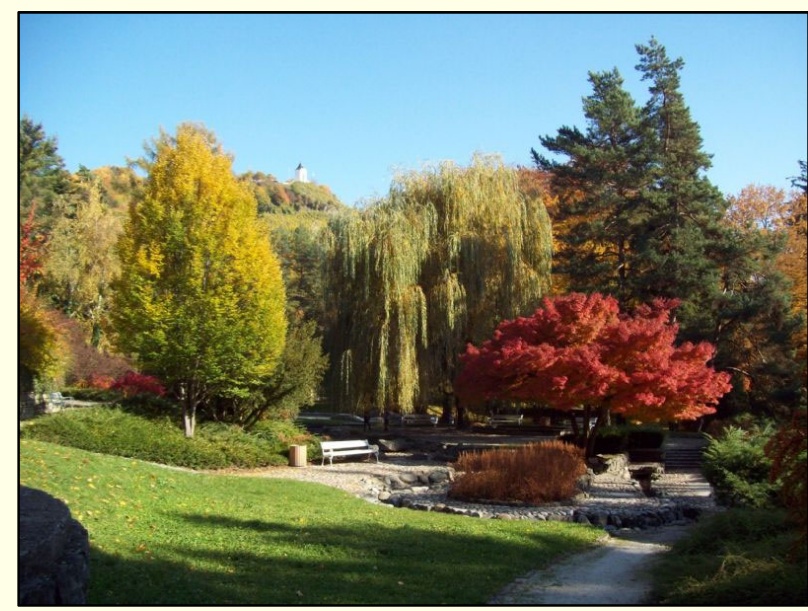

Slika 3: Estetsko urejen mestni park Maribor (Vir: www.hotelbau.si/okoli-maribora).

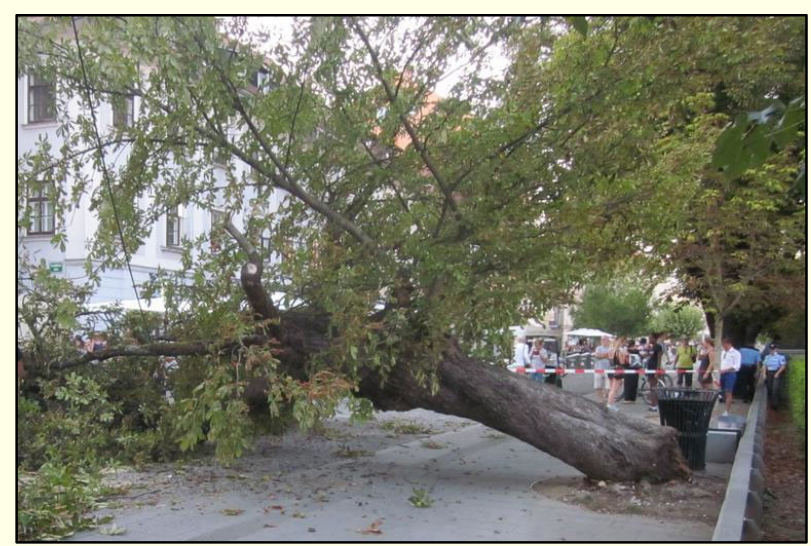

Slika 5: Padlo drevo v središču Ljubljane (Vir: siol.net).

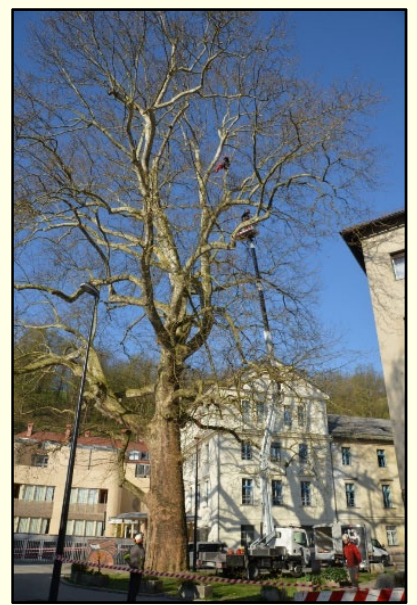

Slika 7: Delo arborista zahteva tudi delo na višini (Vir: tisa.si). celostne in poglobljene obravnave drevesa lahko optimalno ocenimo njegovo stanje in izberemo (ali ne) ustrezne ukrepe.

\section{${ }^{1}$ Gozdarski inštitut Slovenije, Večna pot 2, 1000 Ljubljana *andreja.kavcic@gozdis.si}

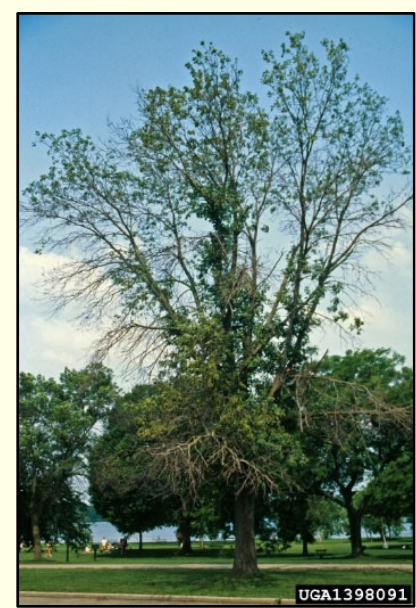

Slika 4: Sušenje vej zaradi napada drevesnega škodljivca (Foto: Steven Katovich, USDA Forest Service, Bugwood.org).

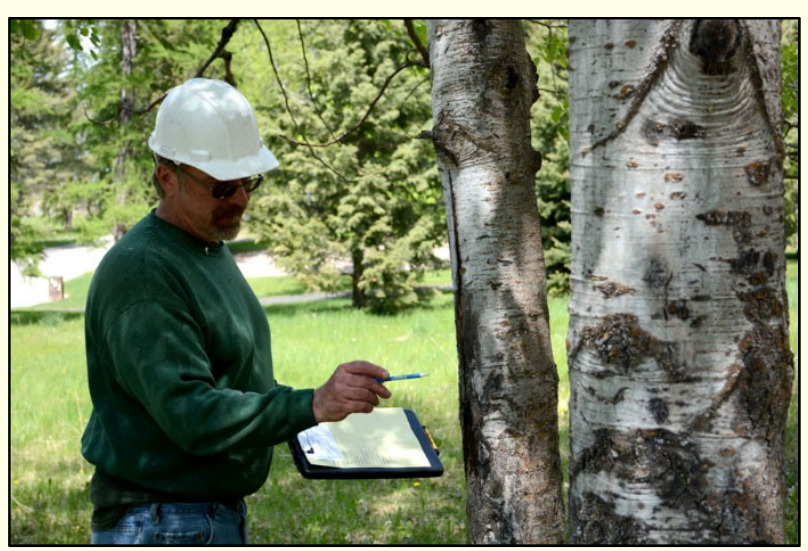

Slika 6: Arborist natančno pregleda drevo in oceni njegovo stanje (Vir: experttreecarellc.com/assessment/).

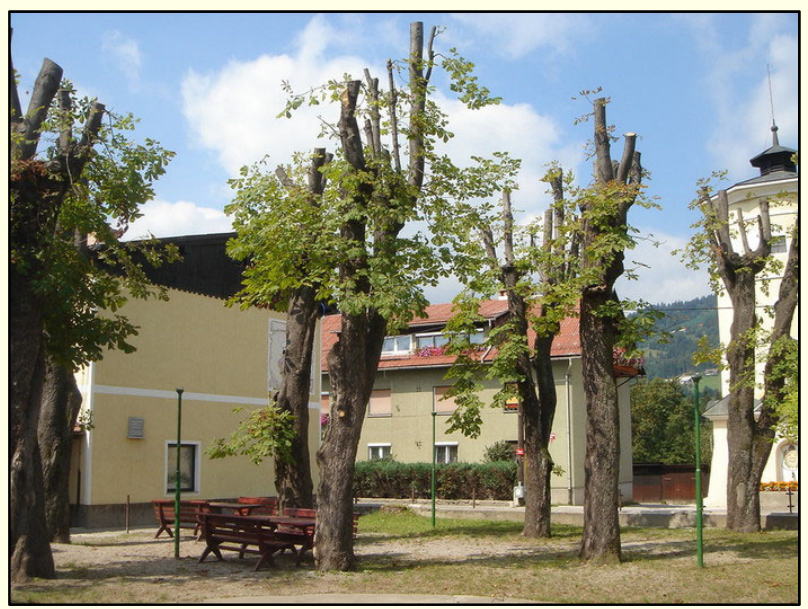

Slika 8: Nepravilno vzdrževana drevesa ne morejo opravljati svojih funkcij (Vir: omorika.si). 


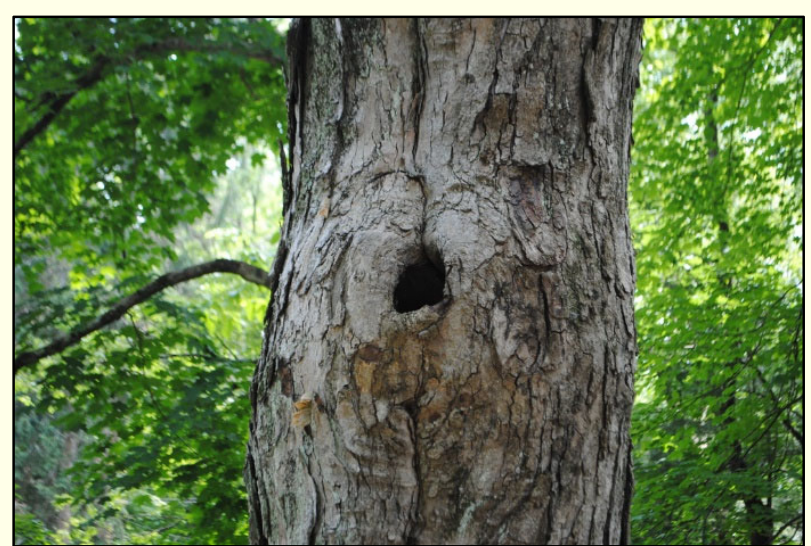

Slika 9: Vsakršne neporavilnosti na drevesu zahtevajo natančen pregled

(Vir: newleaftreeservicesinc.com/tree-risk-assessment/).

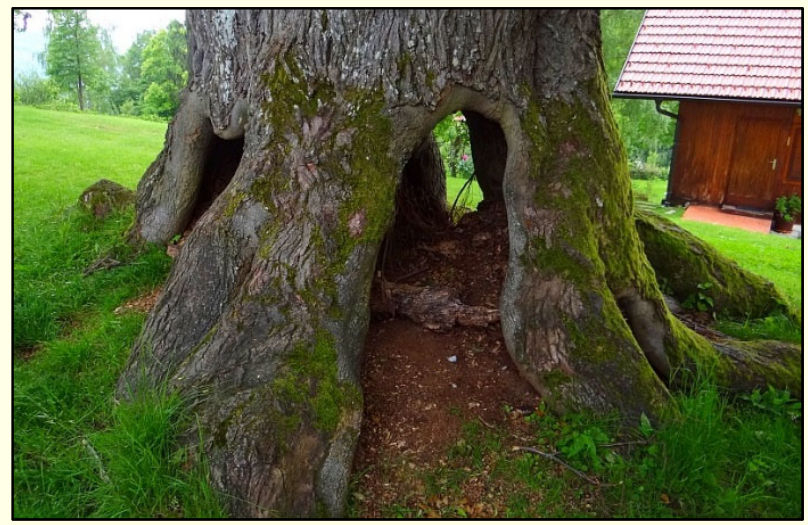

Slika 11: Zaradi obsežnih izvotlitev stara drevesa niso nujno manj stabilna (Vir: http://www2.arnes.si/ gljsentvid10/opazovanja_30 31maj2014_smohor_uni3 poljanska.html).

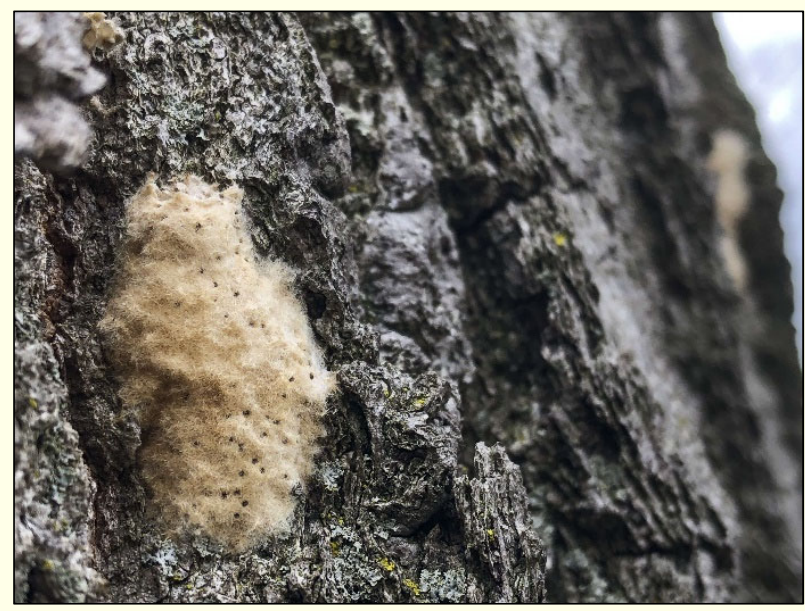

Slika 13: Jajčna masa gobarja (Lymantria dispar), katerega gosenice povzročajo defoliacijo (izgubo listov) dreves različnih vrst listavcev in imajo močno alergene dlačice (Foto: Ernest Doroszuk, torontosun.com).

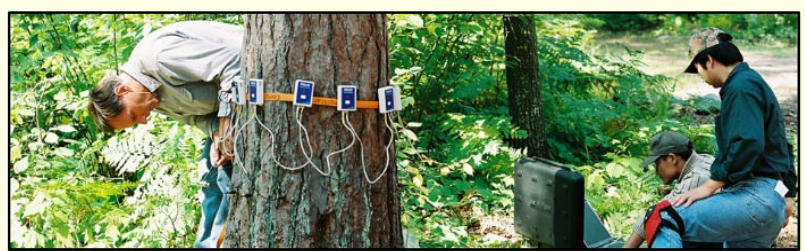

Slika 10: Arboristi za ocenjevanje stanja drevesa uporabljajo posebne naprave (Vir: allisontree.com).

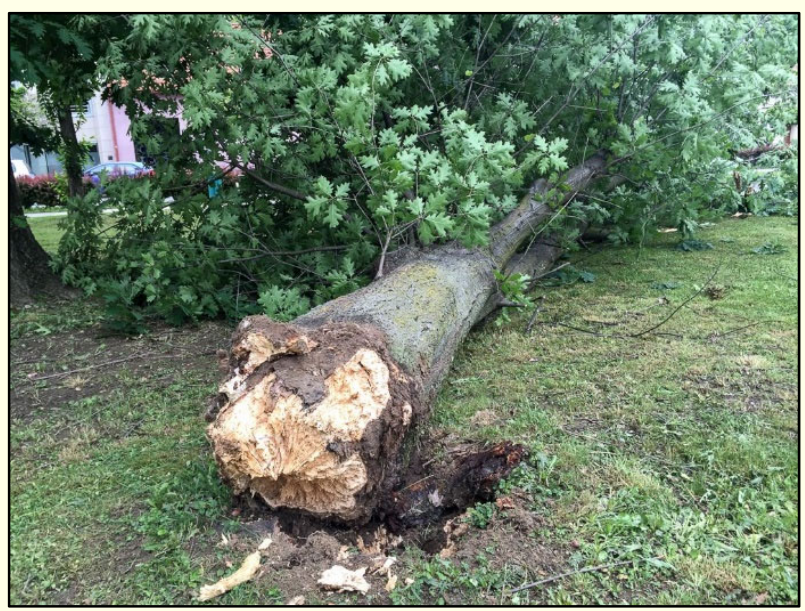

Slika 12: Sredi Murske Sobote se je zaradi trohnobe korenin podrl na videz povsem zdrav hrast (Vir: sobotainfo.com). 